\title{
Experimental Implementation of a Low-Cost Single Phase Five-Level Inverter for Autonomous PV System Applications Without Batteries
}

\author{
Ayoub Nouaiti \\ Laboratory of Energy and \\ Electrical Systems (LESE) \\ Superior National School of \\ Electricity and Mechanical \\ (ENSEM) \\ University of Hassan II \\ Casablanca \\ Casablanca, Morocco
}

\author{
Abdallah Saad \\ Laboratory of Energy and \\ Electrical Systems (LESE) \\ Superior National School of \\ Electricity and Mechanical \\ (ENSEM) \\ University of Hassan II \\ Casablanca \\ Casablanca, Morocco
}

\author{
Abdelouahed Mesbahi \\ Laboratory of Energy and \\ Electrical Systems (LESE) \\ Superior National School of \\ Electricity and Mechanical \\ (ENSEM) \\ University of Hassan II \\ Casablanca \\ Casablanca, Morocco
}

\author{
Mohamed Khafallah \\ Laboratory of Energy and \\ Electrical Systems (LESE) \\ Superior National School of \\ Electricity and Mechanical \\ (ENSEM) \\ University of Hassan II \\ Casablanca \\ Casablanca, Morocco
}

\begin{abstract}
This paper presents the design and the implementation of a low-cost single phase five-level inverter for photovoltaic applications. The proposed multilevel inverter is composed of a simple boost converter, a switched-capacitor converter, and an H-bridge converter. An efficient control method which associates a closed-loop regulation method with a simple maximum power point tracking (MPPT) method is applied in order to allow the proposed multilevel inverter to transfer power energy from solar panels to autonomous load with no storage batteries. An experimental prototype of this inverter is fabricated at the laboratory and tested with a digital control system. Obtained results confirm the simplicity and the performance of the proposed photovoltaic system.
\end{abstract}

Keywords-Multilevel inverter; Boost converter; Switched capacitor converter; $M P P T ; P V$

\section{INTRODUCTION}

Power inverters are mostly used in photovoltaic systems to convert the DC power energy from solar panels to an AC form while respecting the standard criteria for voltage, frequency, and total harmonic distortion (THD). Classical power inverters structures present many problems such as high switching losses, high level of THD, output filters with high sizes [1]. Multilevel inverters present many advantages compared to classical ones [2]. Classical multilevel inverters are systematized in three categories: Flying Capacitor, Neutral Point Clamped Inverter, and Cascaded H-Bridge Inverter [3]. Several structures of multilevel inverters can be deduced from these categories by using, hybrid, symmetric, and asymmetric adjustment [4]. From hybrid adjustment, an important structure is derived: the switched-capacitor converter (SCC) used in two ways: either as a step-up converter or as a multilevel converter tied with classical inverters to get multi-level AC waveforms [5]. Non-isolated DC-DC converters such as classical boost converters (BC) are frequently used between solar panels and multilevel converters structures for low and medium power- levels applications in order to increase the used DC-Bus voltage. These converters are chosen for their simplicity, low manufacturing cost, and low weight [6].

This paper presents the design and experimental test of a simple single phase five-level inverter for Photovoltaic (PV) system applications. An efficient control method which incorporates an MPPT method with a closed-loop regulation method is used. The key part of this inverter is the SCC which is used to tie a $\mathrm{BC}$ with a classical H-bridge converter (HBC). By utilizing this structure, the duty cycle of the control signal of the $\mathrm{BC}$ will be smaller, thus reducing the switching losses across its power switch, the total number of power switches with their gate-drivers power supply is reduced compared to conventional multilevel inverters. The proposed inverter is tested experimentally under industrial values of voltage and frequency by feeding power energy from solar panels to a $130 \mathrm{~W}$ single phase induction motor driving a water pump.

\section{DESCRIPTION OF THE PROPOSED MULTILEVEL INVERTER}

The topology of the proposed PV multilevel inverter is shown in Figure 1. It's composed of a single DC voltage source from solar panels (Vpv), a DC-DC BC circuit, a DC-AC fivelevel converter (FLC) circuit, and an AC single-phase load.

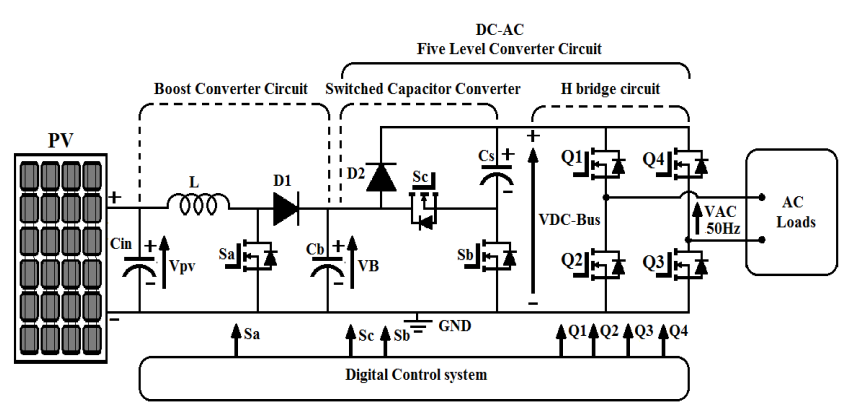

Fig. 1. Topology of the PV multilevel inverter. 


\section{A. DC-DC Boost Converter Circuit}

The $\mathrm{BC}$ is used to increase the input voltage $\mathrm{Vpv}$ to a specified output voltage VB by controlling the switch Sa with a PWM signal [6]. The expression of the output voltage VB from this converter is:

$$
\mathrm{VB}=\frac{\mathrm{Vpv}}{(1-\mathrm{D})}
$$

where $\mathrm{D}$ is the duty cycle of the PWM signal.

\section{B. DC-AC Five-Level Converter Circuit}

The proposed DC-AC FLC circuit is composed of an SCC tied with an HBC. The SCC is used to deliver an output voltage (VDC-Bus) two times greater than the input voltage VB (from the $\mathrm{BC}$ ) by controlling the power switches $\mathrm{Sb}$ and $\mathrm{Sc}$ with complementary pulses $[5,7]$, while the $\mathrm{HBC}$ is used to convert the generated DC-Bus voltage to an AC voltage.

The SCC operates in two modes:

- Charge mode: the switch $\mathrm{Sb}$ is $\mathrm{ON}$; the switch $\mathrm{Sc}$ is OFF. The diode D2 is forward biased. In this mode, the capacitor Cs is charged by VB. The expression of the DC-Bus voltage is:

$\mathrm{VDC}-\mathrm{Bus}=\mathrm{VCs}=\mathrm{VB}$

- Discharge mode: the switch $\mathrm{Sc}$ is $\mathrm{ON}$; the switch $\mathrm{Sb}$ is OFF. The diode D2 is reversely biased. In this mode, the capacitor $\mathrm{Cs}$ is discharged. By considering the value of VCs from (2), the new expression of the DCBus voltage is:

$\mathrm{VDC}-\mathrm{Bus}=\mathrm{VB}+\mathrm{VCs}=2 \mathrm{VB}$

Table I resumes the switching states of the power switches of the DC-AC FLC circuit.

TABLE I. SWITCHING STATES OF THE POWER SWITCHES

\begin{tabular}{|c|c|c|c|c|c|c|}
\hline \multicolumn{6}{|c|}{ SWITCHING STATES } & \multirow[b]{2}{*}{ VAC } \\
\hline Q1 & Q2 & Q3 & Q4 & Sb & Sc & \\
\hline ON & OFF & $\mathrm{ON}$ & OFF & OFF & $\mathrm{ON}$ & $+2 \mathrm{VB}$ \\
\hline $\mathrm{ON}$ & OFF & $\mathrm{ON}$ & OFF & $\mathrm{ON}$ & OFF & $+V B$ \\
\hline OFF & $\mathrm{ON}$ & $\mathrm{ON}$ & OFF & OFF & OFF & $\mathbf{0}$ \\
\hline $\mathrm{ON}$ & OFF & OFF & ON & OFF & OFF & $\mathbf{0}$ \\
\hline OFF & $\mathrm{ON}$ & OFF & ON & $\mathrm{ON}$ & OFF & $-V B$ \\
\hline OFF & ON & OFF & ON & OFF & $\mathrm{ON}$ & $-2 V B$ \\
\hline
\end{tabular}

The SCC has two important aspects in the proposed inverter. The first aspect is to tie the used BC with the HBC by using a small duty cycle (D), while the second is to deliver a special DC-Bus voltage to the HBC in order to get output AC voltage with five-levels, because if the inverter is composed just of a BC and an HBC which is the classical topology. The $\mathrm{BC}$ will operate with high duty cycle, and the $\mathrm{HBC}$ will deliver just an output $\mathrm{AC}$ voltage with two or three levels. In order to obtain the gate pulses of the power switches used in the DCAC FLC circuit by considering the switching states shown in Table I, a simple modulation technique (PWM) is applied (Figure 2). It consists of comparing a reference rectified sinusoidal signal (Ref) with frequency of $50 \mathrm{~Hz}$ with two identical high-frequency triangular carrier signals (Carr1 and Carr2) [8].

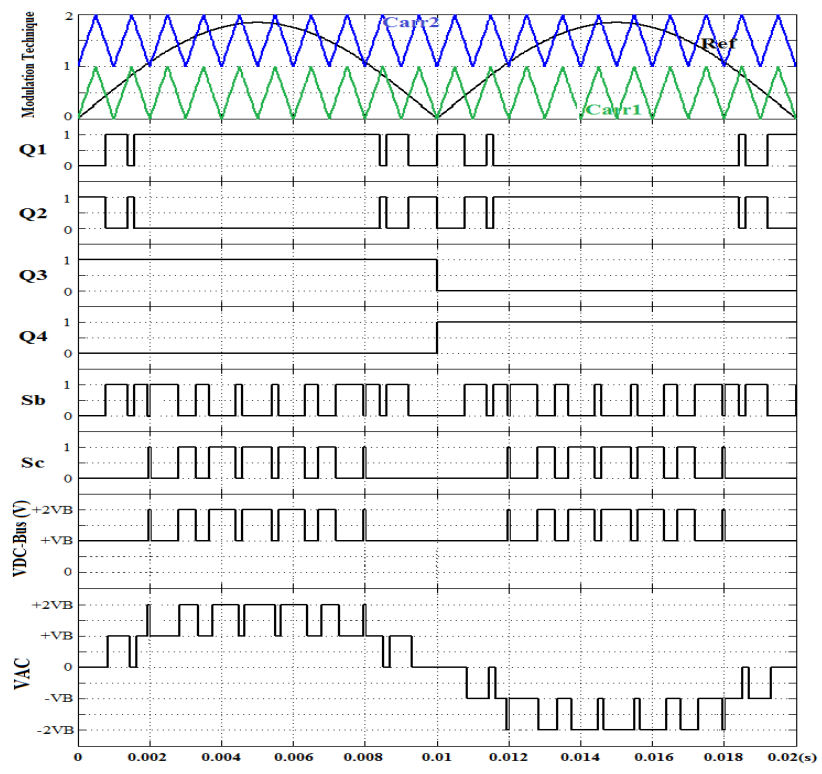

Fig. 2. Used PWM method with the gate pulses, and generated output AC voltage.

By adjusting the modulation index (MI) (4) of the used PWM method, the RMS value of the output AC voltage is controlled.

$$
\mathrm{MI}=\frac{\mathrm{AM}}{2 \mathrm{AC}}
$$

where $\mathrm{AC}$ and $\mathrm{AM}$ are respectively the amplitude of the carrier signals and the reference signal.

\section{CONTROL METHOD FOR AUTONOMOUS PV SYSTEM APPLICATION WITHOUT BATTERIES}

In PV systems, MPPT methods are used to extract maximum power energy available across solar panels under all climatic conditions. In this paper, the used MPPT method is Perturb and Observe (P\&O) [9], the flowchart of which is shown in Figure 3. Simplicity and easy implementation are important advantages of this method. In the case of autonomous PV system application with no storage batteries, the application of the chosen MPPT method on the BC circuit will allow the studied system to deliver maximum power energy to the loads. However, the output voltage of the BC will change depending on the climatic conditions. In order to fix a nominal voltage that the $\mathrm{BC}$ never exceeds, a closed loop regulation control system will be added with the MPPT method. Figure 4 shows the flowchart of the proposed control method, and Figure 5 shows its application with the studied inverter. $\mathrm{BC}$ is controlled to deliver an output voltage $\mathrm{VB}$ which will never exceed a limit (VB-Ref), and the DC-AC FLC is controlled with a fixed MI. As a result, the RMS value of the output AC voltage will also never exceed a limit. 


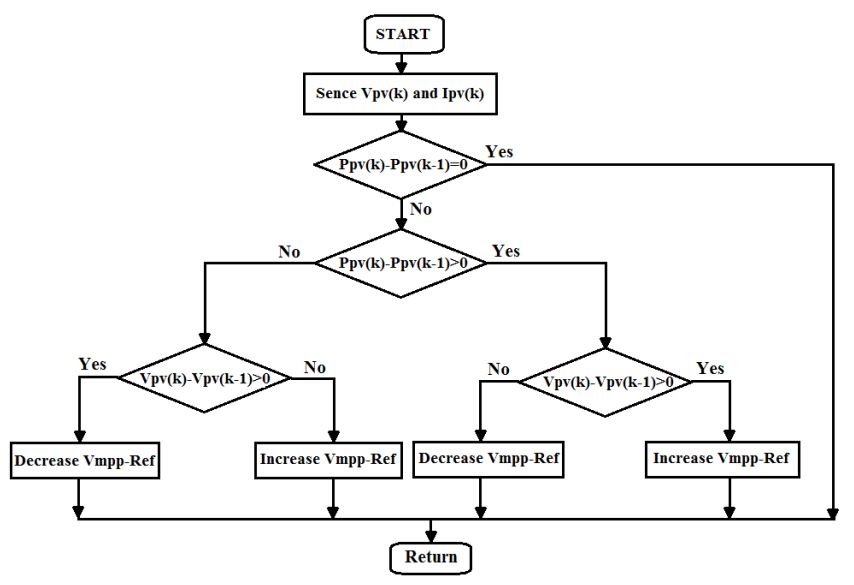

Fig. 3. Flowchart of the "P\&O" method

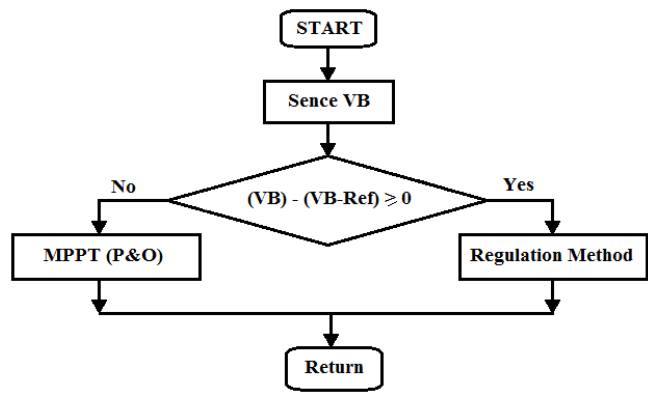

Fig. 4. Flowchart of the proposed control strategy.

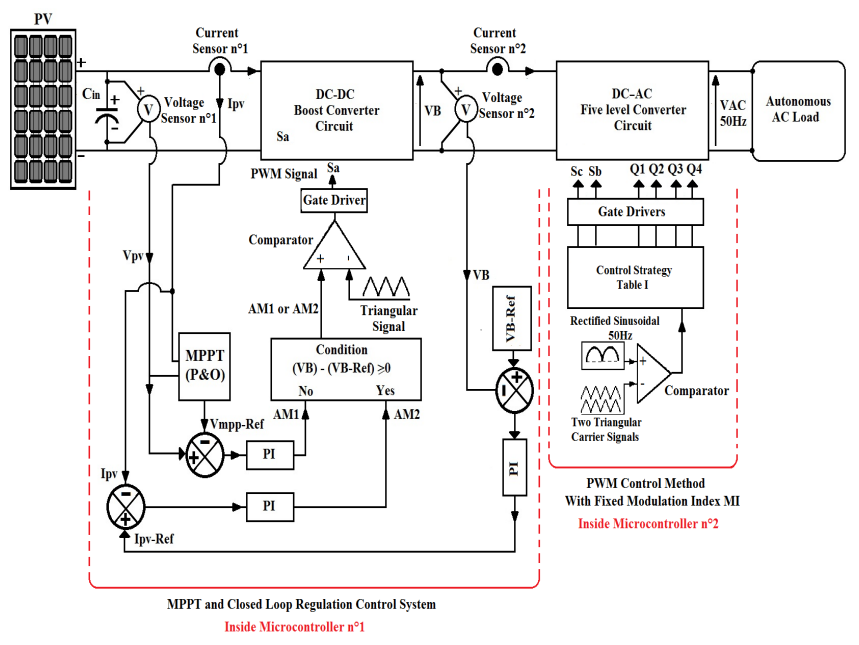

Fig. 5. The proposed control strategy with the studied PV system.

In order to interpret the operation of the PV system with the proposed control method, the autonomous AC load is selected to utilize specific power energy $(\mathrm{Pn})$ under an $\mathrm{AC}$ voltage with a specific RMS value when the output voltage of the $B C$ is equal to VB-Ref.

Regulation mode: When maximum power energy across solar panels (Pmax) is higher than Pn, the PV system starts working with the MPPT until the voltage VB is greater than or equal to VB-Ref, at this time, the control method switches from the MPPT mode to the regulation mode, as shown in Figure 4. In this case, the $\mathrm{BC}$ is controlled with the signal AM2, this signal is generated with the help of two PI regulators: the first PI regulator minimizes the error between the sensed voltage VB and VB-Ref, and the second PI minimizes the error between the generated reference current Ipv-Ref from the first PI and the sensed current Ipv, as shown in Figure 5 [10].

MPPT mode: When Pmax is lower than Pn, the voltage VB will never overtake VB-Ref; the $\mathrm{BC}$ is controlled with the signal AM1, this signal is generated by a PI regulator that minimizes the error between Vmpp-Ref from the MPPT block and Vpv, as shown in Figure 5 [11]. Another act of this PI regulator is to make the response faster of the MPPT block to any sudden and quick variation of climatic conditions.

From the descriptions above, the selected signal (AM1 or AM2) will be compared to a high-frequency triangular signal in order to deliver the PWM signal with the appropriate duty cycle for the BC, as shown in Figure 5.

\section{EXPERIMENTAL RESULTS}

The proposed multilevel inverter is designed and fabricated at the laboratory for a rated power of $250 \mathrm{~W}$, as shown in Figure 6. Two microcontrollers are used as digital control system. The first one is used to control the $\mathrm{BC}$, and the second one is used to control the DC-AC FLC. Two voltage sensors are used for measuring $\mathrm{Vpv}$ and $\mathrm{VB}$. Two current sensors are used for measuring Ipv and the output current of the $\mathrm{BC}$. The power switches $\mathrm{Sa}, \mathrm{Sb}, \mathrm{Q} 2$, and Q3 have a common source with the ground of the input DC voltage (Figure 1). A common power supply for the gate-drivers is used.

Table II resumes values of the used components with their costs. In order to test the robustness of the proposed control method implemented on the microcontrollers, the MPPT method and the regulation method are tested separately before using them in one program. The regulation method (Figure 5) is implemented on the microcontroller $n^{\circ} 1$ using two digital PI regulators. VB-Ref is set to $168 \mathrm{~V}$. Figure 7 shows the used test bench. A digital oscilloscope (DO) is used to record the experimental results, it contains two channel for measuring (ch1 and ch4).

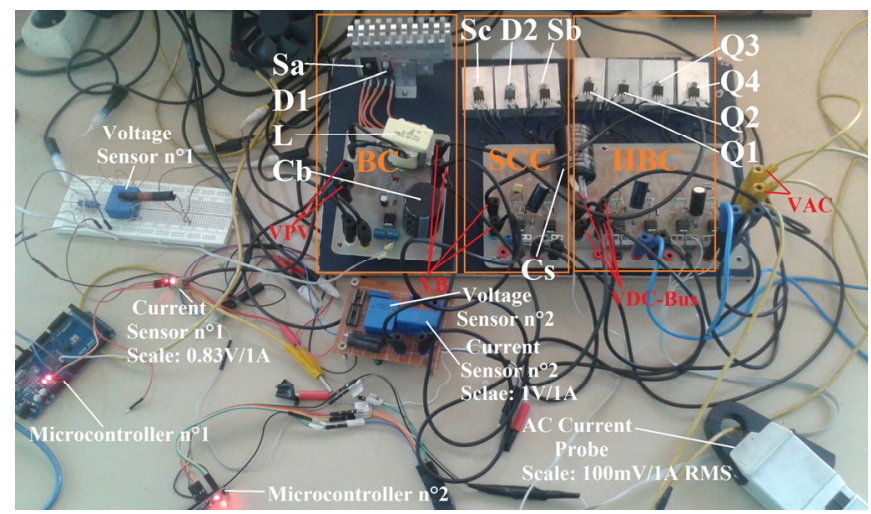

Fig. 6. Fabricated prototype of the photovoltaic multilevel inverter. 
TABLE II. COSTS OF COMPONENTS

\begin{tabular}{|c|c|c|c|}
\hline Components & $\begin{array}{c}\text { No. of } \\
\text { items }\end{array}$ & $\begin{array}{c}\text { Parameters } \\
(\mathbf{2 5 0 W})\end{array}$ & $\begin{array}{c}\text { Costs (€) } \\
(\mathbf{2 5 0 W})\end{array}$ \\
\hline Switch Sa & 1 & SPW47N60C3 & $\begin{array}{c}3.713 \text { (with } \\
\text { gate driver) }\end{array}$ \\
\hline $\begin{array}{c}\text { Switches(Sb, Sc, Q1, } \\
\text { Q2, Q3, and Q4) }\end{array}$ & 6 & STP10NC50 & $\begin{array}{c}6 * 2.938 \text { (with } \\
\text { gate drivers) }\end{array}$ \\
\hline Inductor L & 1 & $6 \mathrm{mH}$ & 24.00 \\
\hline $\begin{array}{c}\text { Capacitors } \\
\text { (Cb and Cs) }\end{array}$ & 2 & $750 u f / 450 \mathrm{~V}$ & $2 * 4.60$ \\
\hline Diodes (D1 and D2) & 2 & BYT12P & $2 * 1.59$ \\
\hline
\end{tabular}

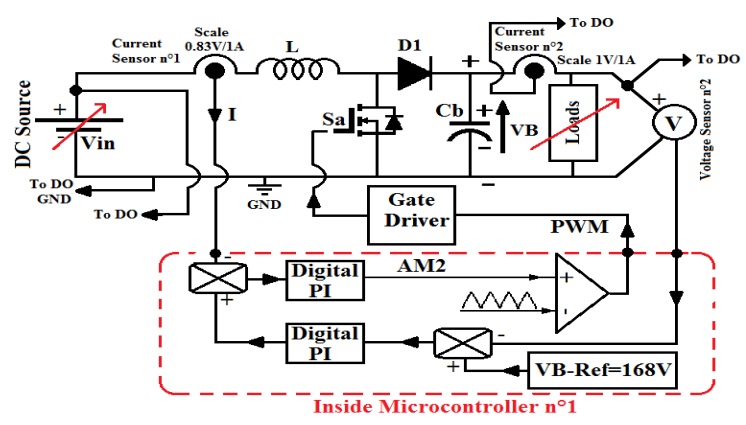

Fig. 7. The test bench used to validate the regulation program.

\section{A. Validation of the Regulation Method}

Two tests are used to validate the regulation method program.

Test1: The load is constant with a rated power of $80 \mathrm{~W}$ and the input voltage (Vin) is variable. Figure 8 and 9 show the regulated output voltage $\mathrm{VB}$ with the variation of the input voltage from $63 \mathrm{~V}$ to $33 \mathrm{~V}$ and from $33 \mathrm{~V}$ to $63 \mathrm{~V}$ respectively.

Test2: The input voltage Vin is fixed at $63 \mathrm{~V}$ and the load is variable (the rated power changes between $50 \mathrm{~W}$ and $170 \mathrm{~W}$ ). Figures 10 and 11 show the regulated output voltage VB with the variation of the output current from $0.25 \mathrm{~A}$ to $1 \mathrm{~A}$ and from $1 \mathrm{~A}$ to $0.25 \mathrm{~A}$ respectively.

From Test 1 and Test 2, the output voltage VB is regulated at $168 \mathrm{~V}$ despite the variation of the input voltage and the load proving the robustness of the implemented digital regulation program.

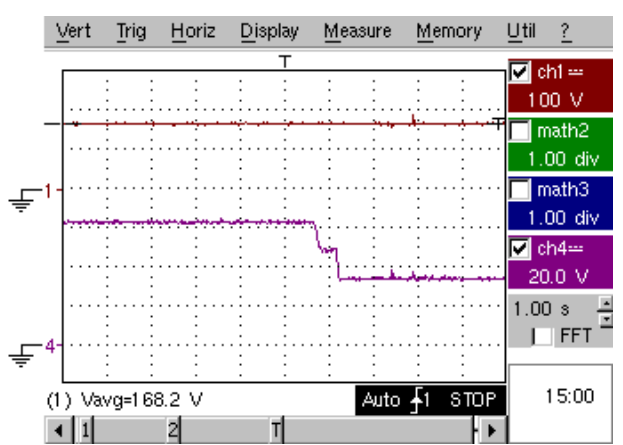

Fig. 8. Regulated output voltage VB (ch1) and input voltage (ch4)

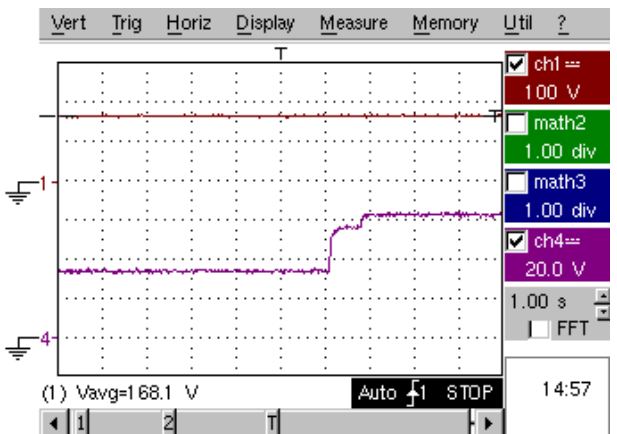

Fig. 9. Regulated output voltage VB (ch1) and input voltage (ch4)

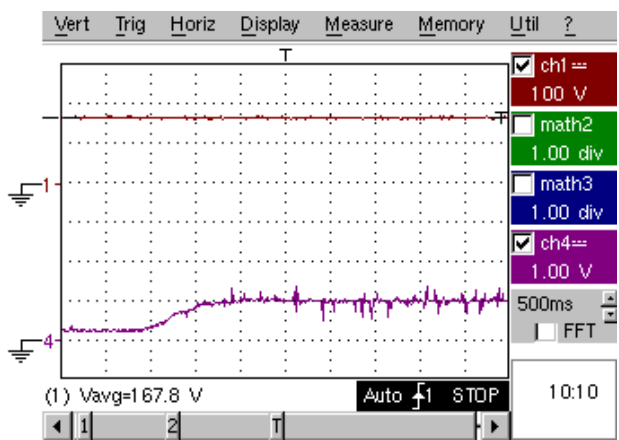

Fig. 10. Regulated output voltage VB (ch1) and output current (ch4)

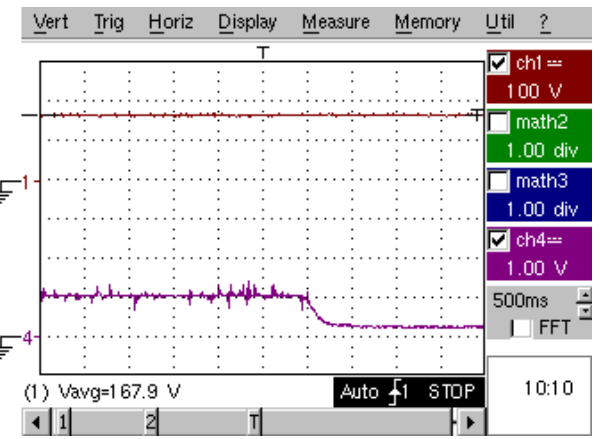

Fig. 11. Regulated output voltage VB (ch1) and output current (ch4)

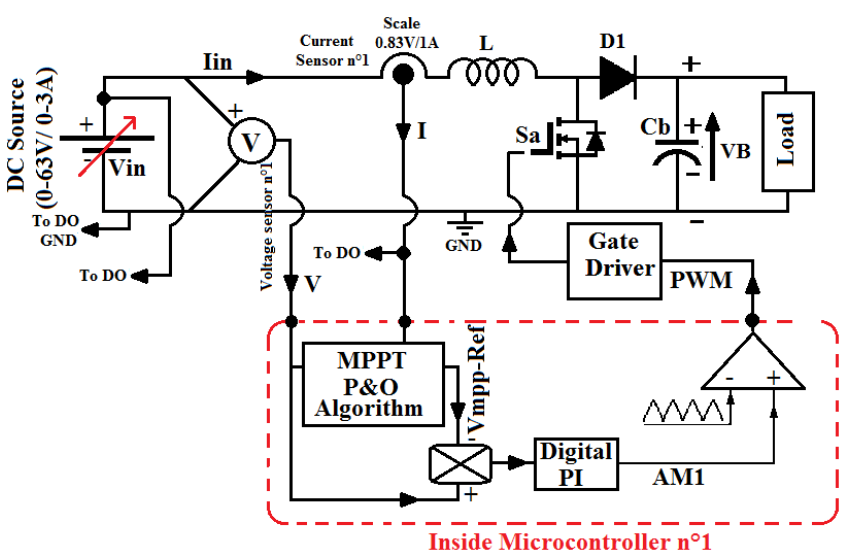

Fig. 12. The test bench used to validate the MPPT program. 


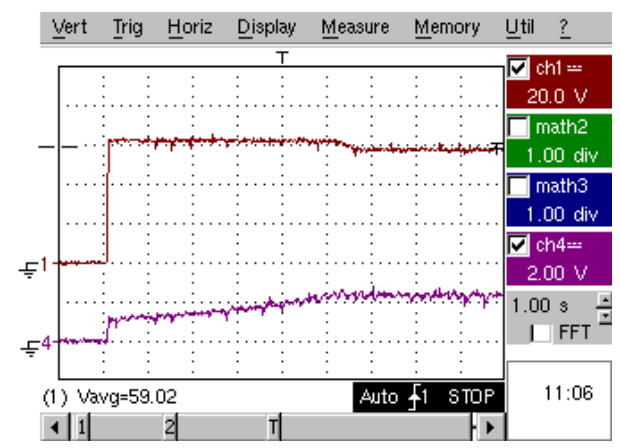

Fig. 13. Regulated voltage Vin (ch1) and input current Iin (ch4).

\section{B. MPPT Validation}

The MPPT method shown in Figure 5 is implemented on the microcontroller $\mathrm{n}^{\circ} 1$ using a digital PI regulator. The load is constant with a rated power of $200 \mathrm{~W}$. The objective of this test is to stabilize the input voltage from a variable DC source at a chosen Vmpp-Ref (59V) and extract the maximum current (3A). Figure 12 shows the used test bench, and Figure 13 shows the obtained input voltage Vin with the delivered maximum current. The MPPT program stabilizes the input voltage from $63 \mathrm{~V}$ to $59 \mathrm{~V}$ fast, and the input current oscillates around the maximum value (3A) prooving proves the robustness of the implemented digital MPPT program.

\section{MPPT and Regulation Validation}

The MPPT and the regulation method are implemented in one program inside the microcontroller $\mathrm{n}^{\circ} 1$ using the condition shown in Figure 4. Figure 14 shows the used test bench.

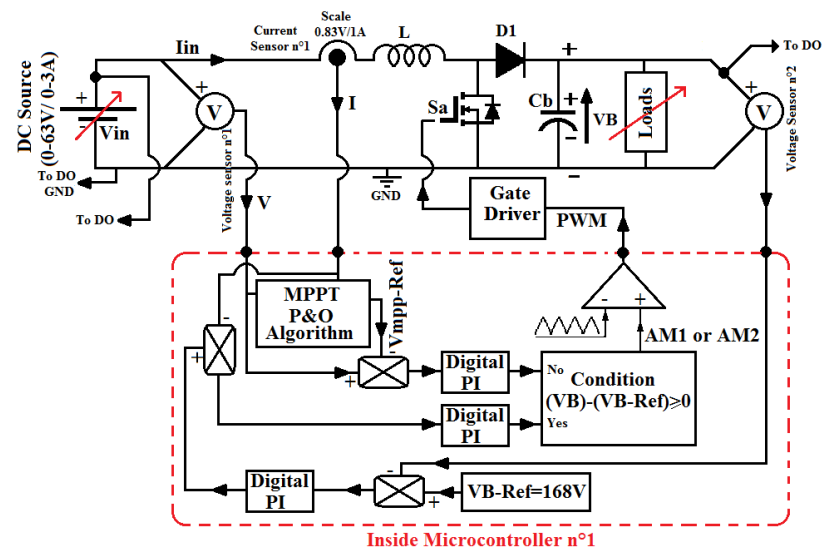

Fig. 14. The test bench used to validate the MPPT program with the regulation program.

In this test, two cases are discussed:

Case1 (Regulation Mode): the maximum power energy from the variable DC source (Pmax-dc) under 59V (VmppRef) is $177 \mathrm{~W}$ for this; the system is tested with a $130 \mathrm{~W}$ rated power $(\mathrm{Pn})$ load. VB-Ref is set to $168 \mathrm{~V}$. Figure 15 shows the values of the output voltage VB stored in Microsoft excel in real time using PLX-DAQ software, and Figure 16 shows the variation of the output voltage $\mathrm{VB}$ and the variation of the input voltage Vin in the DO.

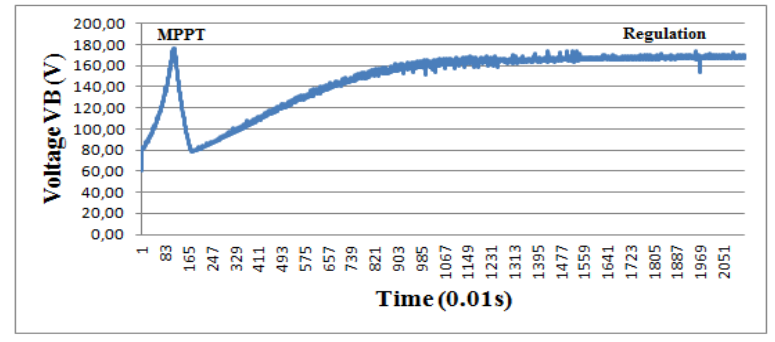

Fig. 15. Recorded output voltage VB.

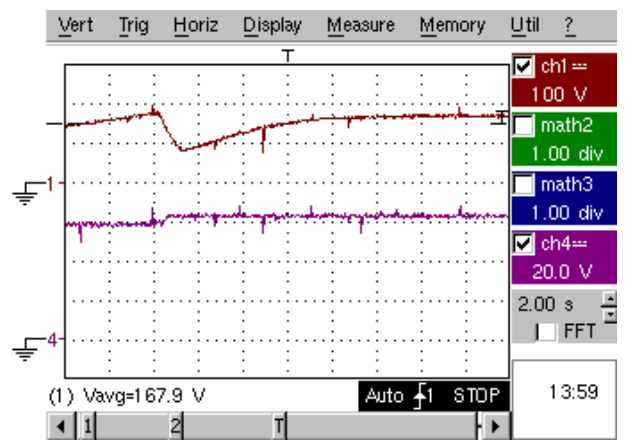

Fig. 16. Output voltage VB (ch1) and input voltage Vin (ch4).

From Figures 15 and 16, the system starts with MPPT program. Input voltage is equal to Vmpp-Ref $(59 \mathrm{~V})$ and the voltage VB increases. When the voltage VB is equal to $168 \mathrm{~V}$ (VB-Ref) the program switches from MPPT to regulation mode. The voltage $\mathrm{VB}$ is regulated at $168 \mathrm{~V}$ and the input voltage changes to $63 \mathrm{~V}$.

Case2 (MPPT Mode): the system is tested firstly with a load where its rated power $\mathrm{Pn}$ is $130 \mathrm{~W}$, which means that the voltage VB will take the same values as seen in Case1. After some time, the rated power Pn is changed suddenly to $200 \mathrm{~W}$. Figure 17 shows the variation of the output voltage VB and the variation of the input voltage Vin under this test. From Figure 17 , when Pn changes from $130 \mathrm{~W}$ to $200 \mathrm{~W}$, the voltage VB decreases, the program switches from regulation mode to MPPT mode and the input voltage changes from $63 \mathrm{~V}$ to $59 \mathrm{~V}$ (Vmpp-Ref). In this case, the voltage VB increases again but never exceeds VB-Ref $(168 \mathrm{~V})$ because $\mathrm{Pn}$ is greater than Pmax-dc.

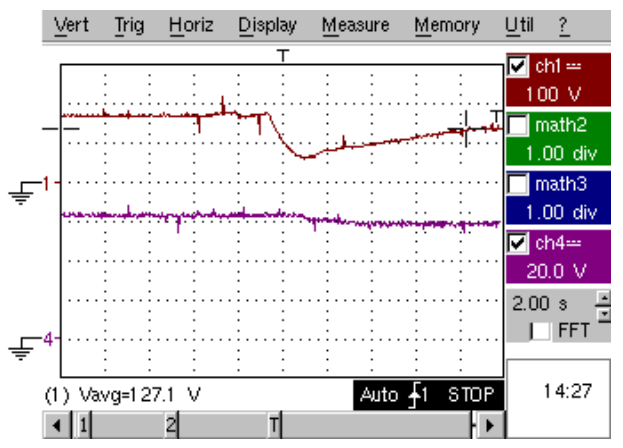

Fig. 17. Output voltage VB (ch1) and input voltage Vin (ch4). 


\section{Full PV System Test}

The full PV system (Figure 5) is tested with a $130 \mathrm{~W}$ single phase induction motor driving a water pump. Two solar panels (240Wp for each one) are used as a DC source for the PV system (Figure 18). The PWM method of the DC-AC FLC is programmed inside the microcontroller $\mathrm{n}^{\circ} 2$ with a fixed MI of 0.92 and a switching frequency of $2 \mathrm{KHz}$ (Frequency of Carr signals), the output frequency is set to $50 \mathrm{~Hz}$, and the VB-Ref of the $\mathrm{BC}$ is fixed to $168 \mathrm{~V}$. From these parameters, the RMS value of the output $\mathrm{AC}$ voltage will be limited to $220 \mathrm{~V}$. The full PV system is tested under optimal climatic conditions. The system starts with MPPT program and when the voltage VB reaches VB-Ref, the control system switches to regulation mode. Obtained voltage VB is similar to the results presented in Figures 15-16. Figure 19 resumes all results obtained when the motor is running under regulation mode. From these results the SCC delivers a DC-Bus voltage which begins from 168V and ends at $336 \mathrm{~V}$ repeated at each half period $(0.01 \mathrm{~s})$, the output AC voltage has a shape with five levels obtained by converting the staircase waveform of the DC-Bus voltage to an alternative form with the $\mathrm{HBC}$, the RMS value of this $\mathrm{AC}$ voltage is $220 \mathrm{~V}(50 \mathrm{~Hz})$, the output AC current is sinusoidal without using filters, and its RMS value is $1.22 \mathrm{~A}$, the FFT spectrum shows that the even harmonics are absent, the first important odd harmonics (3rd and 5th) are very low and the other odd harmonics are moved to the high frequency. The implemented digital control method provides the possibility to benefit from both MPPT and regulation advantages because the use of MPPT method alone without batteries the problem of overvoltage can happen at the output terminal of the $\mathrm{BC}$ when Pmax from solar panels becomes greater than Pn of the load. Also, the use of regulation method alone will pose the problem of over-currents from solar panels which can reach the shortcircuit values (Isc) when Pmax becomes less than Pn.

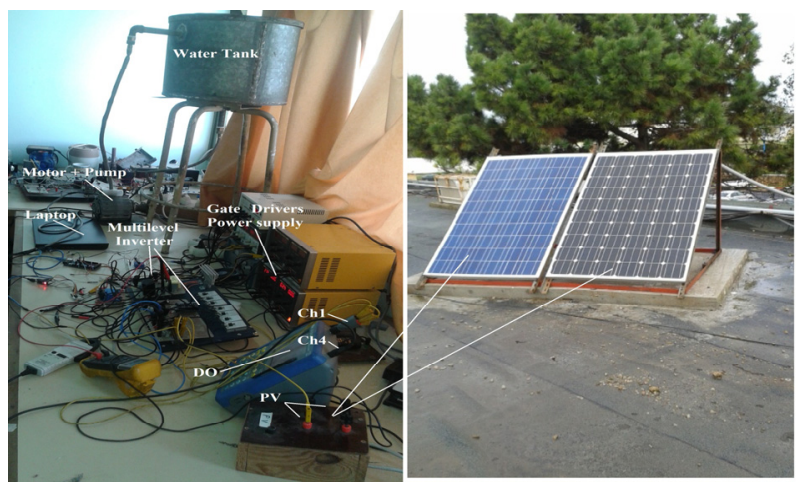

Fig. 18. The two solar panels installed at the laboratory roof with the full PV system.

\section{CONCLUSION}

An experimental test of a low-cost single phase five-level inverter for PV system applications was presented. A switched capacitor converter is used in this photovoltaic inverter to tie a classical boost converter with an $\mathrm{H}$-bridge converter in order to use a small duty cycle for high voltage applications, and also to ameliorate the output AC voltage waveform to get five levels. The THD of the output AC waveforms is very low without using filters. The proposed control method is used to extract maximum power energy from solar panels and regulate voltage and current without using batteries. The proposed PV system was tested with industrial values of voltage and frequency $(220 \mathrm{~V}, 50 \mathrm{~Hz})$. This multilevel inverter is able to supply power energy from solar panels to the industrial machines such as induction motors used in PV pumping systems. The future scope of this work is to increase the rated power of this photovoltaic multilevel inverter $(1 \mathrm{KW})$ and to use a DSP card as a digital control system.

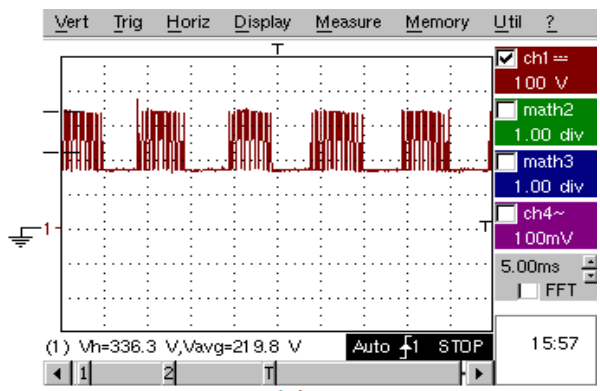

(a)

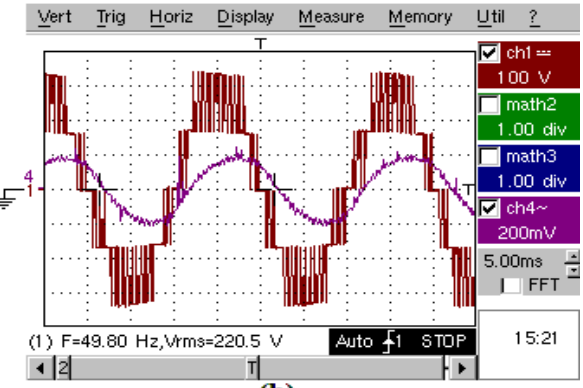

(b)
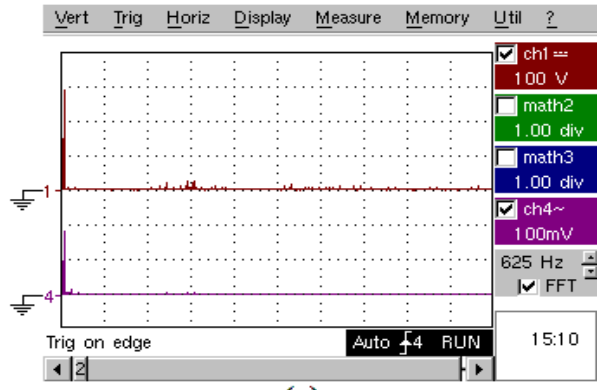

(c)

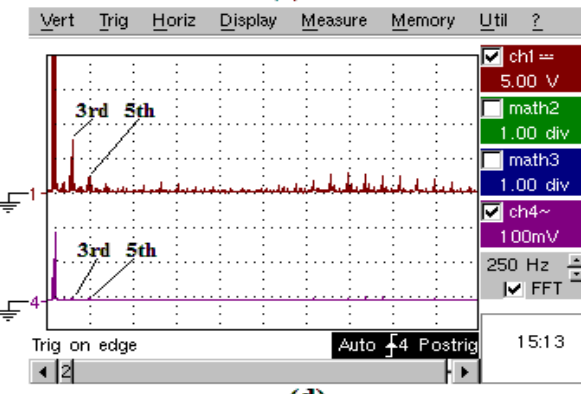

(d)

Fig. 19. (a) DC-Bus voltage; (b) Output AC voltage (ch1) and output AC curent (ch4); (c) The FFT spectrum of the output AC voltage (ch1) and output AC current (ch4); (d) Zoom of the FFT spectrum of the output AC voltage (ch1) and output AC current (ch4) . 


\section{REFERENCES}

[1] U. B. Tayab, M. A. Al Humayun, "Modeling and analysis of a cascaded battery-boost multilevel inverter using different switching angle arrangement techniques", Engineering, Technology \& Applied Science Research, Vol. 7, No. 2, pp. 1450-1454, 2017

[2] A. Nouaiti, A. Saad, A. Mesbahi, M. Khafallah, M. Reddak, "Single phase seven-level inverter for PV solar pumping system", International Renewable and Sustainable Energy Conference, pp. 474-478, 2016

[3] K. K. Gupta, A. Ranjan, P. Bhatnagar, L. K. Sahu, S. Jain, "Multilevel inverter topologies with reduced device count: a review", IEEE Transactions on Power Electronics, Vol. 31, No. 1, pp. 135-151, 2016

[4] N. Prabaharan, K. Palanisamy, "A comprehensive review on reduced switch multilevel inverter topologies, modulation techniques and applications", Renewable and Sustainable Energy Reviews, Vol. 76, pp. 1248-1282, 2017

[5] R. Barzegarkhoo, H. M. Kojabadi, E. Zamiry, N. Vosoughi, L. Chang, "Generalized structure for a single phase switched-capacitor multilevel inverter using a new multiple DC link producer with reduced number of switches", IEEE Transactions on Power Electronics, Vol. 31, No. 8, pp. 5604-5617, 2016
[6] M. Forouzesh, Y. P. Siwakoti, S. A. Gorji, F. Blaabjerg, B. Lehman, "Step-up DC-DC converters: a comprehensive review of voltageboosting techniques, topologies, and applications", IEEE Transactions on Power Electronics, Vol. 32, No. 12, pp. 9143-9178, 2017

[7] A. Nouaiti, A. Saad, A. Mesbahi, M. Khafallah, "Implementation of a single phase switched-capacitor nine-level inverter for PV system applications with selective harmonic elimination", International Journal of Computer Applications, Vol. 168, No. 7, pp. 9-15, 2017

[8] M. A. Sayed, M. Ahmed, M. G. Elsheikh, M. Orabi, "PWM control techniques for single-phase multilevel inverter based controlled DC cells", Journal of Power Electronics, Vol. 16, No. 2, pp. 498-511, 2016

[9] N. Karami, N. Moubayed, R. Outbib, "General review and classification of different MPPT Techniques", Renewable and Sustainable Energy Reviews, Vol. 68, pp. 1-18, 2017

[10] O. Ellabban, O. Hegazy, J. V. Mierlo, P. Lataire, "Dual loop digital control design and implementation of a DSP based high power boost converter in fuel cell electric vehicle", 12th International Conference on Optimization of Electrical and Electronic Equipment, 2010, pp. 610 617,2010

[11] L. Qin, S. Xie, C. Yang, M. Hu, S. Luo, "Design method of input voltage robust PI controller for PV interface converter", International Conference on Renewable Power Generation, pp. 1-6, 2015 